\title{
An android-based mobile educational game for disaster preparedness: an input to risk reduction management
}

\author{
Gene Marck B. Catedrilla ${ }^{1}$, Jefferson L. Lerios ${ }^{2}$, Sherwin B. Sapin ${ }^{3}$, Manuel C. Lanuang ${ }^{4}$, \\ Chester Alexis C. Buama ${ }^{5}$ \\ ${ }^{1,2,3,4}$ College of Computer Studies (CCS), Laguna State Polytechnic University, Los Baños, Laguna, Philippines \\ ${ }^{5}$ College of Arts and Sciences (CAS), Laguna State Polytechnic University, Los Baños, Laguna, Philippines
}

\begin{tabular}{l}
\hline Article Info \\
\hline Article history: \\
Received Jan 13, 2021 \\
Revised Mar 4, 2021 \\
Accepted Mar 13, 2021 \\
\hline
\end{tabular}

\section{Keywords:}

Disaster

Educational game

Mobile game

Preparedness

Risk management

\begin{abstract}
The Philippines is one of the countries in the world who suffers in different disasters, particularly natural disasters. Every year, there are more than twenty incidents recorded in the country related to different disasters which involve numerous lives of its citizens. It is found that most Filipinos have lack of knowledge in terms of disaster preparation specially, teenagers. This paper intended to develop a mobile-based game that aims to spread awareness on what to do during disasters. Upon development, forty-five (45) respondents were chosen to test the reliability of the application which composed of elementary students, household owners, police officers, fire fighters and IT experts. Further, ISO 25010 was adapted and modified in assessing the project. The results showed that the application is strongly acceptable and gives appropriate output in terms of disaster preparation garnering a total mean of 3.83 .
\end{abstract}

This is an open access article under the CC BY-SA license.

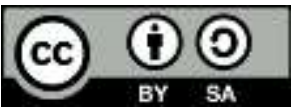

\section{Corresponding Author:}

Gene Marck B. Catedrilla

College of Computer Studies

Laguna State Polytechnic University

Malinta, Los Baños, Laguna, Philippines 4030

Email: catedrilla.genemarck@1spu.edu.ph

\section{INTRODUCTION}

Many people have suffered in the disaster for being not aware or prepared in that case. Philippine atmospheric, geophysical and astronomical services administration (PAGASA) have given the number of typhoons come in the Philippines. There has a total of 17 typhoon hit the Philippines in the year of 2016 [1]. While in the next year, there have 19 typhoons landed on the country. In the past two year they have a total of 36 typhoon touchdown in the Philippines [2]. In fire incidents, there have a total of 19,292 incidents in the year of 2016, 14,197 incidents in the year of 2017 and 15,848 in 2018 [3]. In earthquake, there have a total of 14,474 occurrences come in the Philippines in the past 3 year (2016-2018) [4]-[5].

Disaster is often considered as a problem all over the world. It also creates fewer opportunities, less access to good quality education, jobs and employment. During the interview at provincial disaster risk reduction and management office (PDRRMO) Sta. Cruz Laguna on May 16, 2018, the OIC of PDRRMO department gave the statistical data of Disasters based on categories from year 2015 up to 2017. The Mines and Geosciences Bureau, portions of Sta. Cruz, Calamba City, Bay, Famy, Lumban, Mabitac, Pangil, Pakill, Sinoloan, Sta. Maria, and Sta. Rosa are highly susceptible to flood hazard. Biñan, Cabuyao Calauan, Kalayaan, Liliw, Los Baños, Magdalena, Majayjay, Nagcarlan, Paete, Pagsanjan, Pila, San Pedro, and Victoria are moderately susceptible. San Pablo City, Rizal, Alaminos, Cavinti, and Luisiana, on the other hand are not susceptible to flooding. Out of the 674 barangays in the province, $10 \%$ or 67 barangays are 
highly susceptible, $37 \%$ or 251 barangays are moderately susceptible and $53 \%, 356$ are not susceptible. Some cases and causes of life loss in the Philippines are because of devastating and destructive disasters [5]. Aside from the Philippines, other country in the world also experienced catastrophic natural phenomenon. The hurricane Katrina in the USA, the biggest earthquakes in Asia and Haiti, and the trusnami in Japan and Indonesia [6]. The problem is that, disasters always comes in an unexpected situation, yet many people are lack of knowledge on how to protect themselves or how to become prepared and aware, specifically on how to survive in unexpected situation or in unwanted event [7]. The government always lean their attention in these cases, they always warn and make programs for disaster awareness to help residences of the country on how to be aware and prepared for the upcoming disasters, yet the government initiative and perseverance to save people is not enough [8].

Most of people nowadays are commonly using digital device, some are manipulated by gadgets and other high technology devices [9]. As technology keeps on growing, people are modernized and easily adapt modern technologies. In 2017, the number of smartphone users in the Philippines is estimated to reach 30.4 million [10]. This would mean that around 82 percent of the population in the Philippines would use a Smartphone. This number is expected to rise to 40 percent by the year 2021. In the statistical information about mobile phone users in the Philippines, it shows that the number of users in the Philippines from 2015 to 2016 will get bigger and bigger until 2022.

In this modern society, people do their work faster than man power can do with the help of information technology [11]. It is easy for human to take over jobs because technology makes the work easier, faster and efficient with less error. Except of those advantage and benefits that technology can give, there are more functions that technology can do [12]-[13]. Technology can teach people through mobile applications, especially educational applications. These applications created for good purposes, particularly for teaching and learning. Mobile game is rampant and one of the most famous application worldwide to every child and youth in different countries. It is a good medium for disseminating information around the globe.

With the current state of the country, this paper aims to develop an educational mobile game application regarding natural disaster to promote awareness among the users. In particular, the project will: (a) provide an alternative tool for disseminating information regarding natural calamity through game development, (b) Design an actual occurrence of natural calamities in every level/stages of the game based on the data gathered on the risk reduction office. And lastly; (c) develop a game that will show virtual model of the actual disaster.

\section{RESEARCH METHOD}

The project focus in the development of an educational mobile-game for disaster preparedness among elementary students in the Philippines. This is to improve the cognitive skills of the students in terms of disaster response before and after it is occurred [14]. The user can access and view all the interface and functions of the game. Before playing the game, the user must have a smartphone with the minimum specification. The android application will show the user interface where the user can see the settings wherein the volume of the game's music can be adjusted, and the current high score can be viewed. Levels contains all the levels of every category. Data gathered in the PDRRMO is used as basis in every scenario or level of the game [15]. Concept of the mobile game as shown in Figure 1.

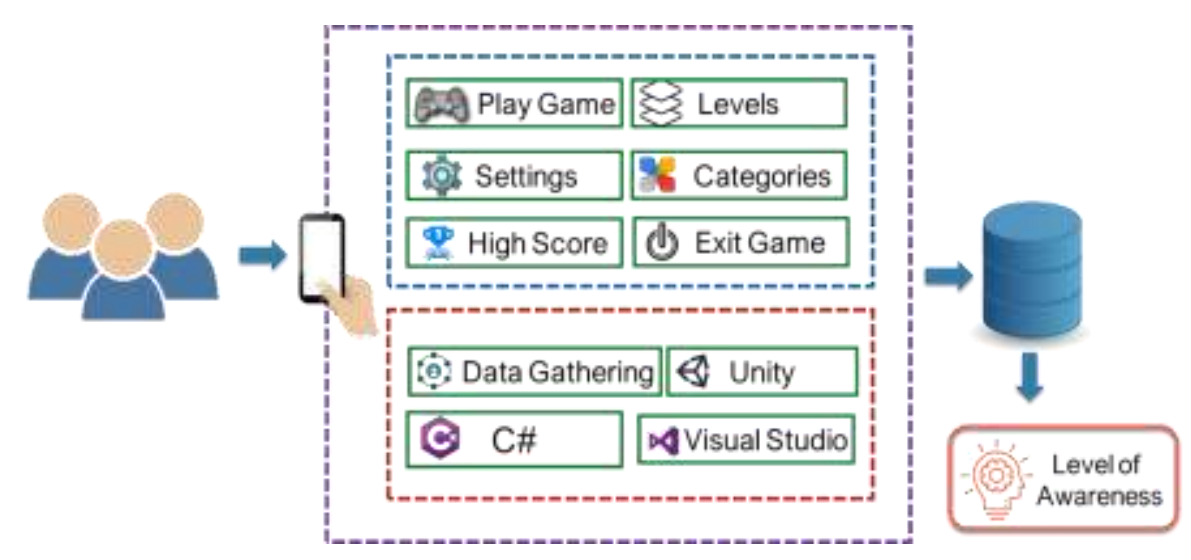

Figure 1. Concept of the mobile game 
The highly recommended application for developing game is unity-a multipurpose game engine that support $2 \mathrm{~d}$ and $3 \mathrm{~d}$ graphic design, it also allows specification of texture compression, mini maps, bump mapping, reflection mapping, parallax mapping, screen space ambient occlusion and the resolution setting of the game. The game is developed following a linear design which is common in different software development. It is compressed in three different phases namely; planning, design and implementation, and evaluation.

\subsection{Planning}

Report of the Philippines disaster risk reduction management office for the recent years is gathered to have a basis on what are the usual causes of severity of incidents to its casualties. Relevant and substantial materials are also identified in this part to assure that the software will be delivered accurate and reliable [16].

\subsection{Design and implementation}

System architecture shows the modules inside the game as shown in Figure 2. It has three (3) different modules; stage category, game settings and level of awareness result, which are all developed through the use of unity software. design and implementation involve coding and testing of software. Testing focuses on the relevance of code and compatibility of the game to different android versions and specification.

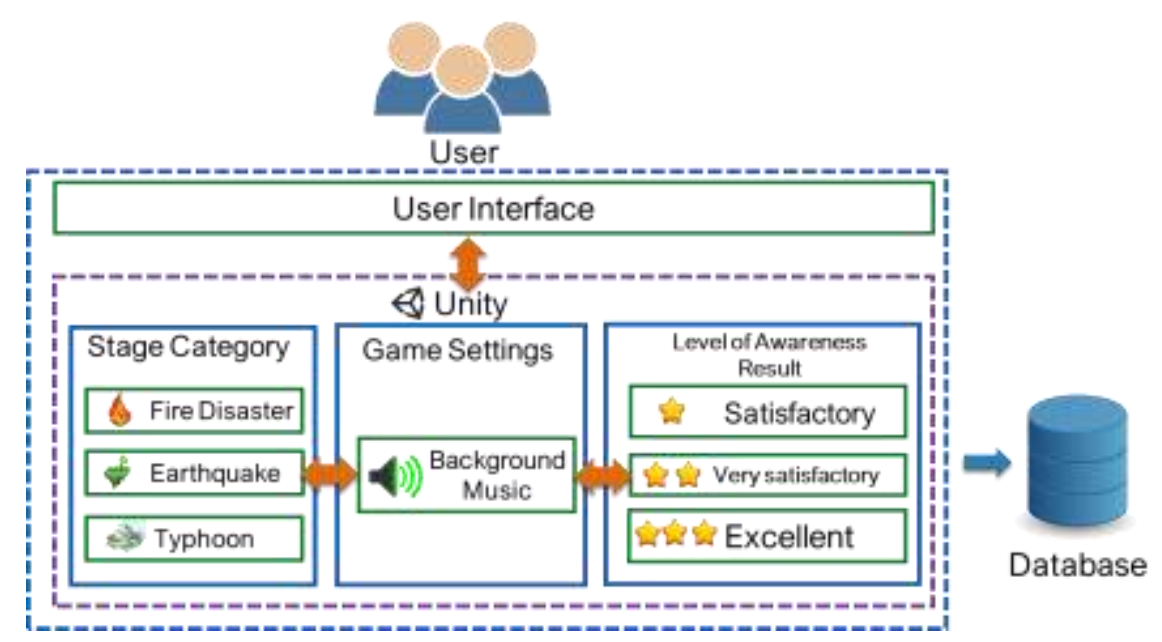

Figure 2. System architecture of the game

\subsubsection{Stage category}

There are three (3) different disasters that is included to the game; fire, earthquake and typhoon which are common in the Philippines. These disasters were named category in this project, also, each category correspond to the level inside the game. The users will not be able to access the next category unless the first one is finished. This is to ensure that the users or the students will be capable or understanding the first category before moving forward to another one.

\subsubsection{Game settings}

Game settings is the module where the users are capable of turning on the background music of the game or putting it on mute.

\subsubsection{Level of awareness result}

In level of awareness result module, a rating will be given to the user base on its performance in every category. The user's awareness was quantified by the game through the stages. The game will allow the user to move forward to another stage when it successfully got the correct way in every disaster. In this way, if the user did not have any idea on what to do with each disaster, it will not be allowed to do the next task which will be the process on disseminating information on what to do during the actual disaster [17]-[19]. 


\subsection{Evaluation}

Upon the development of the project, it will be tested by different elementary school students and teacher in the municipality of Los Baños, province of Laguna in the Philippines. A questionnaire is created by adapting the ISO 25010 or the software standard evaluation [20]-[21] as shown in Figure 3. In the evaluation process, students who were in grades 1-4 will be guided in answering the question to understand the question thoroughly [22]-[23]. The evaluation purpose is to identify if it is a qualified full game, free of bugs and error, and lastly, if the game meets its objective. Percentage method is adapted to interpret the evaluation results of the system, Likert Scale in Table 1.

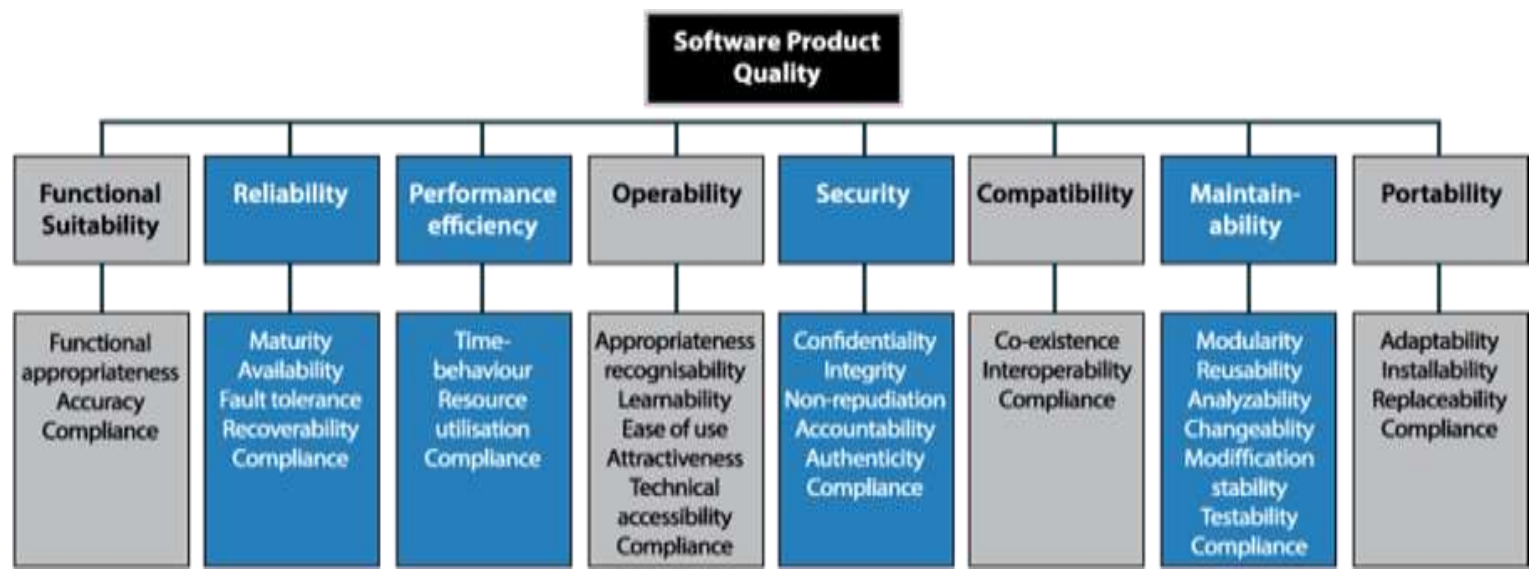

Figure 3. ISO 25010 model

$$
\%=\frac{\mathrm{f}}{\mathrm{N}} \times 100
$$

Where:

$f=$ Frequency

$N=$ Total Number of Respondents

$$
\frac{\mathrm{X}=(\mathrm{SA} * 4)+(\mathrm{A} * 3)+(\mathrm{D} * 2)+(\mathrm{SD} * 1)}{T N R}
$$

Where:

$X=$ Weight Mean

$T N R=$ Total Number of Respondents

$S A=$ Strongly Agree

$A=$ Agree

$D=$ Disagree

$S D=$ Strongly Disagree

Table 1. Likert scale

\begin{tabular}{ccc}
\hline Rating & Scale Range & Interpretation \\
\hline 4 & $3.51-4.00$ & Strongly Agree \\
3 & $2.51-3.50$ & Agree \\
2 & $1.51-2.50$ & Disagree \\
1 & $1.00-1.50$ & Strongly Disagree \\
\hline
\end{tabular}

\section{RESULTS AND DISCUSSION}

This section will show the result of the development of the mobile game and its evaluation.

\subsection{Game devevlopment}

The game will be called rules of disaster since in aims to provide on what should a person do during a disaster. The landing page contains the other pages of the games namely; start game, settings, highscore, 
credits, and exit game, as shown in Figure 4. In Category page, the three-common disaster in the Philippines are projected. Here, the user can choose on what disaster they want to study or pursue. Every category contains problem that needs to be solve through the correct procedure that is implemented by PDRRMO as sown in Figure 5. In-game scenario is the inside of every category which contains an actual scenario of particular disaster. The problem must be solved by the user to move-on to another level. It can be solved by following the protocols recommended by the PDRRMO as shown in Figure 6.

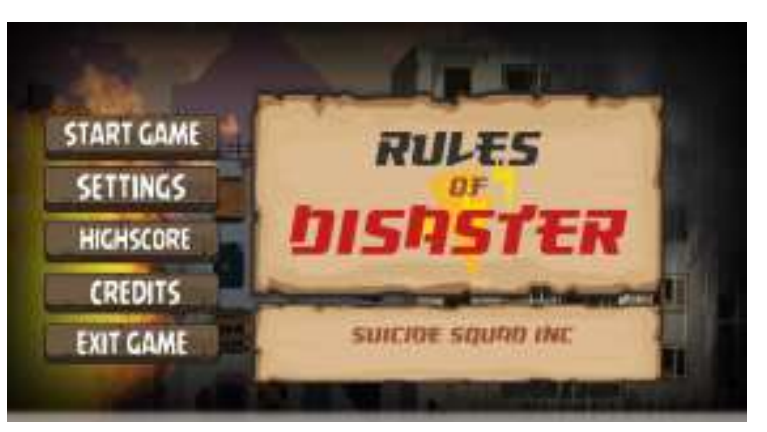

Figure 4. Landing page of the game

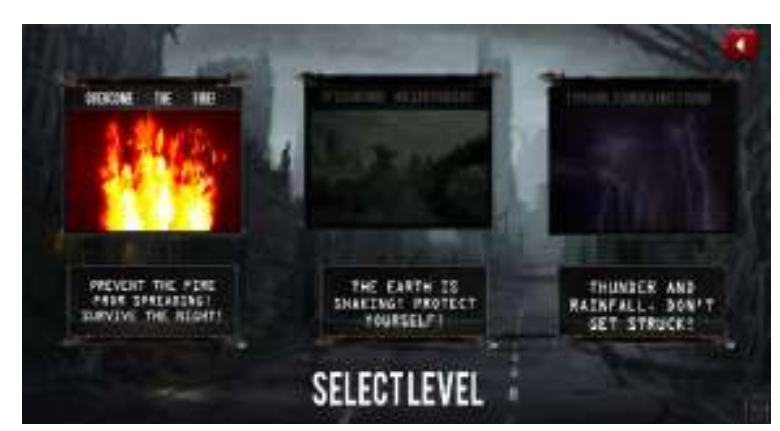

Figure 5. Category page of the game

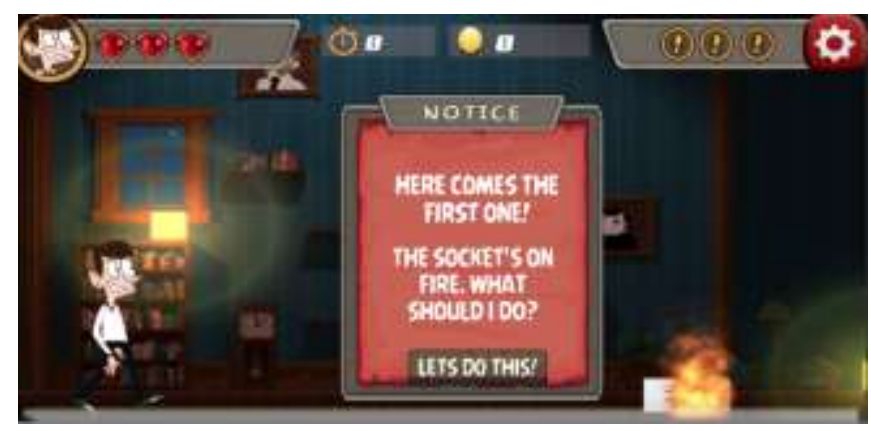

Figure 6. Sample in-game scenario to be solved by the user

\subsection{Forward and backward testing of the game}

The application is developed in android version 6.0 or Marshmallow which will be the center of the forward and backward testing. During backward testing, it is found out that the game cannot be installed in android version 4.1-4.4.4 which are android Jellybean and Kitkat. However, the game is installed and working smoothly in version 5.0 which is the android Lollipop, as shown in Table 2. In forward testing, the educational game work finely and successfully installed in android version 7.0 and up which is the android Nougat and the following versions, as shown in Table 3.

Table 2. Summary of results of testing in lower version of android operating system

\begin{tabular}{ccccc}
\hline Android Version & Process & Expected Result & Actual Result & Remarks \\
\hline v.4.1-4.3.1 (Jellybean) & Install & Will successfully installed & Compatibility error & Failed \\
v.4.4-4.4.4 (KitKat) & Install & Will successfully installed & Compatibility error & Failed \\
v.5.0-5.1.1 (Lollipop) & Install & Will successfully installed & Installed & Success \\
\hline
\end{tabular}

Table 3. Summary of result of testing in higher version of android operating system

\begin{tabular}{ccccc}
\hline Android Version & Process & Expected Result & Actual Result & Remarks \\
\hline v.7.0-7.1.2 (Nougat) & Install & Will successfully installed & Installed & Success \\
v.8.1-8.1 (Oreo) & Install & Will successfully installed & Installed & Success \\
v.9.0(Pie) & Install & Will successfully installed & Installed & Success \\
\hline
\end{tabular}




\subsection{Evaluation of the game}

The game is introduced to all the respondents and taught them how to play it. Based on the evaluation of different users, it is shown in Table 4, that the game is acceptable and useful to the users garnering an overall weighted mean of 3.83 [24]. The mobile game is developed with three different modules. Hence, as the main module, category page includes the action that the user may do in times of disaster. The forward and backward testing is done to ensure that that game will reach all the android users in the Philippines. Wherein, it is found out that all the present android version of mobile phones in the country is compatible with the game. A beta test is also conducted in this study to the teachers and students of different primary school in Los Baños, Laguna, Philippines and found that the game is acceptable in the education sector of the country. Further, during the testing the students enjoy playing the game and memorized the requirements of it to forward in the next level [25]-[26].

Table 4. Summary of result of evaluating the system adapting ISO 25010 criteria

\begin{tabular}{ccc}
\hline Factor & Ratings & Interpretation \\
\hline Functional Suitability & 3.84 & Strongly Agree \\
Performance Efficiency & 3.79 & Strongly Agree \\
Compatibility & 3.8 & Strongly Agree \\
Usability & 3.79 & Strongly Agree \\
Reliability & 3.81 & Strongly Agree \\
Security & 3.79 & Strongly Agree \\
Maintainability & 3.96 & Strongly Agree \\
Portability & 3.86 & Strongly Agree \\
Overall weighted mean & 3.83 & Strongly Agree \\
\hline
\end{tabular}

\section{CONCLUSION}

Preparedness is indeed a powerful weapon to mitigate risk during disaster. It is shown in this paper, that game development can be essential in disseminating vital information to the people to raise their awareness in disaster and make them ready during disaster occurrences. After the evaluation process done by different individuals and experts, it is concluded that the developed game is acceptable in different users and can raise awareness for disaster preparedness. The author would like to recommended the use of this game in different elementary students in the Philippines to help them become more knowledgeable on what-to-do during disaster. It is also recommended that the game must be included in the program of PDRRMO in raising awareness.

\section{ACKNOWLEDGEMENTS}

The authors would like to extend their heartfelt gratitude to the provincial disaster risk reduction office of Laguna, Philippines for their efforts to help them in finalizing the concept of the project. Further, the Laguna State Polytechnic University, for the support in finishing the project

\section{REFERENCES}

[1] J. Badal, "How PAGASA Came Up with Such Typhoon Names?" 2017. [Online]. Available: http://aboutcagayandeoro.com/26-typhoon-names-enter-philippines-released-pagasa

[2] D. Esguerra, “Typhoon Names:” 2017. [Online]. Available: https://insidemanila.ph/article/86/2017-typhoon-namesreleased

[3] N. Holden, "Mining amid typhoons: Large-scale mining and typhoon vulnerability in the Philippines". 2017. [Online]. Available: https://www.sciencedirect.com/science/article/pii/S2214790X15000817

[4] T. Noelynna, K. V. Ramos, "Application of the Analytic Hierarchy Process and GIS in Susceptibility Mapping of Earthquake-Triggered $\quad 2013 . \quad$ Landslides". 2 Avline]. http://citeseerx.ist.psu.edu/viewdoc/download?doi=10.1.1.742.1577\&rep=rep1\&type=pdf

[5] P. Pasion, "8 fire incidents in Metro Manila as PH welcomed 2018-BFP," 2018. [Online]. Available: www.rappler.com/nation/192657-fire-incidents-metro-manila-new-year

[6] D. Velev and P. Zlateva, "Use of Social Media in Natural Disaster Management". ICITE 2012 - International Conference on Information Technology and Engineering (ICITE 2012). Hong Kong, 2012.

[7] E. Stikova, "Disaster Preparedness". South Eastern European Journal of Public Health, special volume (2016), no. 2, pp. 120-141. 2016.

[8] J. R. Asor, S. B. Sapin. "Implementation of Predictive Crime Analytics in Municipal Crime Management System in Calauan, Laguna, Philippines". International Journal of Advanced Trends in Computer Science and Engineering, vol. 9, no. 1.3, pp. 150-157, 2020, doi: 10.30534/ijatcse/2020/2291.32020. 
[9] M. Ruchtera, "Comparing the effects of mobile computers and traditional approaches in environmental education". 2010, doi: 10.1016/j.compedu.2009.10.010

[10] J. R. Asor, et al., "Intelligent Investigation on Crime Incident Reports in the Province of Laguna through Predictive Model Development". International Journal of Advanced Trends in Computer Science and Engineering, vol. 9, no. 1.3, pp. 139-144, 2020, doi: 10.30534/ijatcse\%2F2020\%2F2091.32020.

[11] M. A. T. Subion, C. F. Gulay, "iSAFE: A Disaster Management Application Utilizing Georeferencing and A* Algorithm", in CIIS 2018: 2018 International Conference on Computational Intelligence and Intelligent Systems, Phuket Thailand, 2018, doi: 10.1145/3293475.3293488.

[12] M. Mansourvar, N. M. Yasin. "Web portal As A Knowledge Management". World Academy of Science, Engineering and Technology 70 2010, 968-974. 2010, doi: 10.5281/zenodo.1061489.

[13] M. H. Tsai, et al., "Game-based education for disaster prevention", AI \& Soc 30, pp. 463-475, 2015, doi: 10.1007/s00146-014-0562-7.

[14] D. Satria, S. M. Jalil, E. Yusibani. "The Disaster Notification System Based SMS to Students at the School Vulnerable Flood Disaster using Single Board Computer of Raspberry Pi". International Journal of Advanced Trends in Computer Science and Engineering, vol. 9, no. 2, pp. 1063-1067, 2020, doi: 10.30534/ijatcse/2020/25922020.

[15] A. S. Nowak, et al., "An overview of serious games for disaster risk management - Prospects and limitations for informing actions to arrest increasing risk", International Journal of Disaster Risk Reduction, vol. 31, pp. 10131029. 2018, doi: 10.1016/j.ijdrr.2018.09.001.

[16] B. Findlay, "Digital Games in Disaster Preparedness Education". School of EngineeringUniversity of Auckland, 2017, doi: 10.13140/RG.2.2.24698.03527.

[17] L. Maminta, "Level of Awareness on Disaster Preparedness", in 1st UPY International Conference on Applied Science and Education 2018, pp.1-4. 2018.

[18] S. Gerdan, Determination of disaster awareness, attitude levels and individual priorities at Kocaeli University, Eurasian Journal of Educational Research, vol. 55, pp.159-176. 2014.

[19] Y. Dikmenli, H. Yakar, A. Konca, "Development of Disaster Awareness Scale: A Validity and Reliability Study". Review of International Geographical Education Online (RIGEO), vol. 8 no. 2, pp. 206-220. 2018.

[20] L. S. Echalar, M. A. T. Subion, "PaLife: A Mobile Application for Palay (Rice) Health Condition Classification utilizing Image Processing and Pigment Analysis towards Sustainability of Palay Production", in 2018 International Seminar on Research of Information Technology and Intelligent Systems (ISRITI), Yogyakarta Indonesia, 2018, doi: 10.1109/ISRITI.2018.8864286.

[21] G. M. Catedrilla. M. A. T. Subion, "VIP READY: A Mobile Leisure Search Engine for Visually Impaired Persons Utilizing Phone Motion and Speech Recognition", in 2018 International Seminar on Research of Information Technology and Intelligent Systems (ISRITI), Yogyakarta Indonesia, 2018, doi: 10.1109/ISRITI.2018.8864282.

[22] S. Shohieb, "CDMG: Crises and Disasters Management Game (Video Game to Teach Arab Children How to Handle Emergencies and Crises)" 2018 7th International Conference on Software and Computer Applications, pp. 264-268, 2018, doi: 10.1145/3185089.3185147.

[23] E. W. Winarni, et al., "Mobile Educational Game for Earthquake Disaster Preparedness in Elementary School", ARPN Journal of Engineering and Applied Sciences, vol. 13, no. 7, pp. 2612-2618, 2018.

[24] S. C. Lin, et al., "Game-Initiated Learning: A Case Study for Disaster Education Research in Taiwan", in 2013 AAAI Spring Symposium, pp. 67-71, 2013.

[25] C.-H. Huang, S.-M. Chung, M.-C. Hsu, "Computer Games Designed for Disaster Prevention Learning", in 3rd International Conference on Multimedia Technology (ICMT), pp. 1163-1170. 2013, dx.doi.org/10.2991/icmt13.2013.142.

[26] B. Thangagiri, R. Naganathan, "Online Educational Games-Based Learning in Disaster Management Education: Influence on Educational Effectiveness and Student Motivation," 2016 IEEE Eighth International Conference on Technology for Education (T4E), Mumbai, pp. 88-91, 2016, doi: 10.1109/T4E.2016.02.

\section{BIOGRAPHIES OF AUTHORS}

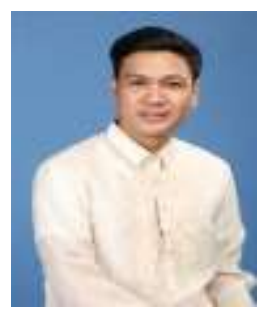

Gene Marck B. Catedrilla is a graduate of Master in Information Technology at the Technological Institute of the Philippines Manila on Octobe 2018. He currently works as College instructor at the Laguna State Polytechnic University Los Baños. Mr. Catedrilla is a member of different national and international professional association related to different research discipline. His research interest is in information technology education and technology aide in person with disability. 

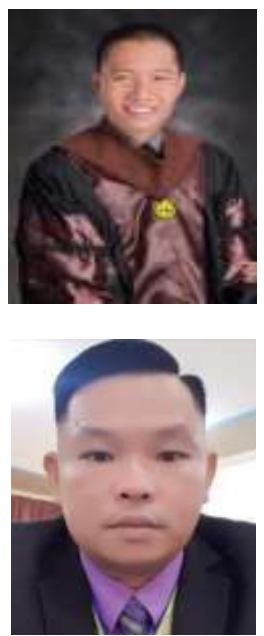

Jefferson L. Lerios is a graduate of Doctor of Information Technology at the Technological Institute of the Philippines Manila. Currently, he is an Assistant Professor II at the College of Computer Studies, Laguna State Polytechnic University-Los Baños Campus. His research interest is in the field of environmental modeling, intelligent systems, information technology, data mining, and data analytics.

Dr. Sherwin Banaag Sapin is currently the Chairperson of the Curriculum and Instruction Development and the Coordinator for Local Government Unit of Laguna State Polytechnic University-Los Baños Campus; Lead Accreditor of the Accrediting Agency of Chartered Colleges and Universities in the Philippines, Incorporated (AACCUP, Inc.); Assistant Professor IV and former Research Implementing Unit Head and Coordinator for the Curriculum and Instruction Development and Quality Assurance of the College of Computer Studies; Affiliate professor in the Graduate Studies and Applied Research; Former Public Information Officer of the Federated Faculty Association of Laguna State Polytechnic University; former Chairperson of the Information and Communications Technology (ICT) Services; His research interests are in Information Technology Education, Mathematics Education, and Educational Management; He authored various research studies published in different international journals.

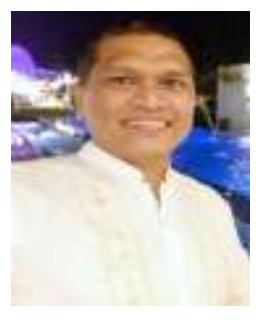

Manuel C. Lanuang is a graduate of Master of Arts in Education major in Educational Management at the Laguna State Polytechnic University-Los Baños. Currently, he is pursuing his Master of Science in Information technology at the Laguna State Polytechnic University-San Pablo Campus and affiliated as Gender and Development coordination of CCS-LSPU LB. His research interest is in the field of information technology, software development and learning management systems.

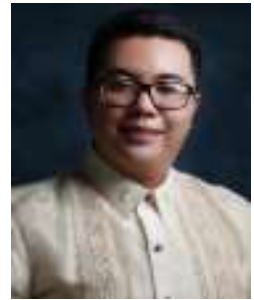

Dr. Chester Alexis C. Buama is a College Professor at Laguna State Polytechnic University under the Faculty of College of Arts and Sciences. A Consultant of the Department of Education Central Office for Learning Assessment and National Trainer of the Commission on Higher Education for General Education Courses. He is also a member of local and international organizations: he is a Fellow and Senior Member of the Royal Institute of Management and the Royal Institute of Educators, Singapore, Reading Association of the Philippines, and International English Learners Training Institute. He was a Philippine Youth Ambassador to ASEAN countries and Japan which was sponsored by the Cabinet Office of Japan and Office of the President of the Philippines in 2010. He has a Master's degree in Management major in Public Administration and a Bachelor's degree in Journalism. He was conferred a Doctorate Degree in Philosophy major in Public Administration in 2016 and graduated with a Doctorate Degree in Philosophy major in Business Management in 2018. His research interest is in Social Science, and Business Management. 